\title{
Patent Ductus Arteriosus: Perinatal Risk Factors
}

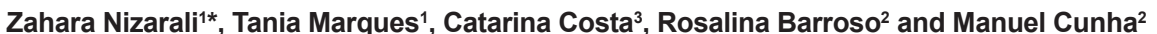

${ }^{1}$ Pediatric Department, Hospital Professor Doutor Fernando Fonseca, EPE, Amadora, Portugal

${ }^{2}$ Neonatal Intensive Care Unit, Hospital Professor Doutor Fernando Fonseca, EPE, Amadora, Portugal

${ }^{3}$ Statistical Department, Hospital Professor Doutor Fernando Fonseca, EPE, Amadora, Portugal

\section{Summary}

Background: Patent Ductus Arteriosus (PDA) is the most common heart disease among the newborn population. Besides prematurity, other factors are believed to play a significant role in this condition.

Aims: Identification of perinatal risk factors associated with PDA in premature or Very Low Birth Weight Infants (VLBW)

Material and methods: Transversal study including all infants admitted to a Level III Neonatal Intensive Care Unit, from January 2005 to December 2009 and included in the Very Low Birth Weight Portuguese National Database . Clinical and demographic data were analysed using a logistic regression analysis to identify risk factors for PDA.

Results: A total of 318 VLBW or less than 32 weeks Gestational Age (GA) infants were enrolled, $53.6 \%$ males.

Infants presenting PDA $(100 ; 31.4 \%)$ had a lower mean BW ( 914,19 versus 1257,44 grams; $p<0.001$ ) and a lower mean GA (27.06 versus 29.77 weeks; $p<0.0001)$.

Using univariate logistic regression, both lower BW [OR: 0.99; Cl (95\%): 0.995-0.997] and lower GA [OR: 0.68; Cl (95\%): 0.61-0.75] were important risk factors for PDA.

Other factors increasing the risk of PDA were: lower Apgar scores at one [OR: 0.77; $\mathrm{Cl}$ (95\%): 0.68-0.86] and five minutes [OR:0.73; $\mathrm{Cl}(95 \%): 0.62-0.86$ ]; need for resuscitation in the delivery room [OR: $13.1 ; \mathrm{Cl}(95 \%): 3.11-55.1$; surfactant administration [OR:8.12; $\mathrm{Cl}(95 \%): 4.13-15.95]$; higher CRIB score [OR:1.17; $\mathrm{Cl}(95 \%): 1.11-1.24]$, and higher SNAPPEII score [OR: $1.03 ; \mathrm{Cl}(95 \%): 1.02-1.04]$.

The logistic multivariate regression model using all these variables identified BW [OR: 0.997; Cl (95\%): 0.9960.998 ] and surfactant treatment [OR: $3.99 ; \mathrm{Cl}(95 \%): 1.903-8.386$ ] as the only risk factors contributing with statistical significance.

The analysis of the ROC curve showed a predictive positive value of $82 \%$.

Discussion: The most important risk factors were the use of surfactant and BW, the latter increasing by $23 \%$, the risk of PDA for fewer 100 grams. Although surfactant treatment leads to improved respiratory outcomes and survival in VLBW infants, it increased the risk of PDA by an almost fourfold.

Keywords: Patent Ductus Arteriosus (PDA); Very Low Birth Weight (VLBW); Surfactant

\section{Introduction}

The Ductus Arteriosus (DA) is an important vascular connection between the main pulmonary artery and the aorta. During fetal life, the DA diverts blood from the pulmonary artery into the aorta, thereby bypassing the lungs. After birth, the DA undergoes active constriction and eventual obliteration. A Patent Ductus Arteriosus (PDA) occurs when the ductus fails to completely close after delivery.

Fetal patency is regulated by low oxygen tension and prostanoids, predominantly Prostaglandin E2 (PGE2) and Prostacyclin (PGI2). PGE2 and PGI2 levels are high in the fetus because of both placental production and diminished clearance by the fetal lungs [1]. After birth at term, a postnatal increase in $\mathrm{PaO}_{2}$ and a decrease in circulating vasodilators such as PGE2 and PGI2 will induce constriction of DA smooth muscle cells and, consequently, functional closure of the ductus in newborns [2].

The incidence of PDA in term infants has been estimated to be 57 per 1,00,000 live births [3], whereas one in every three preterm infant with a birth weight of 501 to $1500 \mathrm{~g}$ (very low birth weight [VLBW]) can be expected to have a PDA [4,5], contributing to significant morbidity and mortality in preterm infants. The shunting of blood through a PDA in premature infants is essentially all left-to-right.
Subsequently there is an excessive flow through pulmonary circulation and hypoperfusion of the systemic circulation. As such, preterm infants born at $<1500 \mathrm{~g}$ are susceptible to hypoperfusion of vital organs and resultant additional co-morbidities such as IVH (Intraventricular hemorrhage), periventricular leukomalacia, NEC, and (pre) renal failure. However, although PDA is definitely associated with these morbidities, its causal role is not clear [6].

The higher incidence of PDA in preterm infants may be explained by the effect of prematurity on the regulators of ductal tone [7]. In preterm infants, sensitivity for oxygen is reduced while the sensitivity to PGE2, nitric oxide (NO), and perhaps endothelin 1 is increased [8].

*Corresponding author: Zahara Nizarali, Pediatric Department, Hospital Professor Doutor Fernando Fonseca, EPE. IC 19, Venteira, 2720-Amadora, Portugal, E-mail: zahara.nizarali@gmail.com

Received June 29, 2012; Accepted September 14, 2012; Published September 16, 2012

Citation: Nizarali Z, Marques T, Costa C, Barroso R, Cunha M (2012)Paten Ductus Arteriosus: Perinatal Risk Factors. J Neonatal Biol 1:109. doi:10.4172/21670897.1000109

Copyright: (c) 2012 Nizarali Z, et al. This is an open-access article distributed under the terms of the Creative Commons Attribution License, which permits unrestricted use, distribution, and reproduction in any medium, provided the original author and source are credited. 
Glucocorticoids appear to change DA's sensitivity to PGE2. For example, hydrocortisone given to preterm lambs facilitates ductal constriction, probably by decreasing the sensitivity of the ductus to the dilating action of PGE2 [9]. This may explain the lower incidence of PDA in VLBW infants whose mothers received antenatal glucocorticoid treatment [10].

As per the above, mechanisms underlying the functional closure of the DA depend on gestational maturity. Nevertheless, other factors are believed to play a significant role to this condition.

The aim of this article is to identify other perinatal risk factors associated with PDA in premature or very low birth weight infants.

\section{Material and Methods}

All infants admitted to our NICU from January 2005 to December 2009 and included in the Very Low Birth Weight Portuguese National Database were enrolled for a transversal study. The study took place in a level III Neonatal Intensive Care Unit at the Pediatric Department of Professor Fernando Fonseca Hospital, Portugal. We used data pertaining to our NICU that is included in the National Very Low Birth Weight database.

PDA was diagnosed with echocardiogram. Clinical and demographic data were analysed. The differences between groups (with/without PDA) were analyzed applying the Chi-square, T-student or Mann-Whitney tests. Risk and protective factors were identified through the Odds Ratio (OR) obtained with the univariate and multivariate logistic regression. The multivariate logistic model was built using the forward method. The discriminatory power of the model was evaluated using the ROC curve, including the concordance index (area under the curve). The statistical tests were carried out at a significance level of 0.05 using the SPSS 17 software.

\section{Results}

A total of 318 infants with very low birth weight or less than 32 weeks gestational age were enrolled, of which $53.6 \%$ were males. The mean birth weight and gestational age were 1139, 2 grams and 29 weeks respectively (Table 1).

PDA was diagnosed by echocardiogram in 100 infants (31.4\%)

\begin{tabular}{|c|c|c|c|}
\hline & $\begin{array}{l}\text { NO PDA } \\
(\mathrm{N}=218)\end{array}$ & $\begin{array}{c}\text { PDA } \\
(\mathrm{N}=100)\end{array}$ & $p$ \\
\hline Gender (female/male) & $119 / 99$ & $51 / 49$ & $0.31(b)$ \\
\hline Antenatal corticotherapy & $177(81.2 \%)$ & $80(80 \%)$ & $0.4(b)$ \\
\hline Gestational age (mean \pm SD) & $29.7 \pm 2.82$ weeks & $27.06 \pm 2.37$ weeks & $<0.001$ (a) \\
\hline Birth Weight (mean \pm SD) & $\begin{array}{c}1257.44 \pm 326 \\
\text { grams }\end{array}$ & $\begin{array}{c}914.19 \pm 278 \\
\text { grams }\end{array}$ & $<0.001(a)$ \\
\hline Surfactant administration & $80(36.7 \%)$ & $78(78 \%)$ & $<0.001(b)$ \\
\hline APGAR 1' (mean rank) & 175.9 & 116.8 & $<0.001(\mathrm{c})$ \\
\hline APGAR 5' (mean rank) & 176.0 & 116.6 & $<0.001$ (c) \\
\hline CRIB (mean \pm SD) & $2.58 \pm 4.12$ & $5.91 \pm 4.45$ & $<0.001(\mathrm{a})$ \\
\hline SNAPPE II (mean \pm SD) & $27.41 \pm 25.4$ & $48.67 \pm 25.5$ & $<0.001(\mathrm{a})$ \\
\hline Resuscitation with $\mathrm{O}_{2}$ & $171(78.4 \%)$ & $97(97 \%)$ & $<0.001(b)$ \\
\hline Manual ventilation & $70(32.1 \%)$ & $3939 \%)$ & $0.14(b)$ \\
\hline Intubation & $82(61.9 \%)$ & $76(48.1 \%)$ & $<0.001(b)$ \\
\hline Epinhefrine & $7(3.2 \%)$ & $6(6 \%)$ & $0.4(b)$ \\
\hline Chest compressions & $12(5.5 \%)$ & $10(10 \%)$ & $0.2(b)$ \\
\hline
\end{tabular}

$\mathrm{p}^{\mathrm{a}}$ : Two-tailed T-test - analysis of variance of values

$\mathrm{p}^{\mathrm{b}}$ : Chi-square test comparison between groups

$\mathrm{p}^{\mathrm{c}}$ : Mann-Whitney U test

SD: standard deviation

Table 1: Baseline characteristics of study infants.
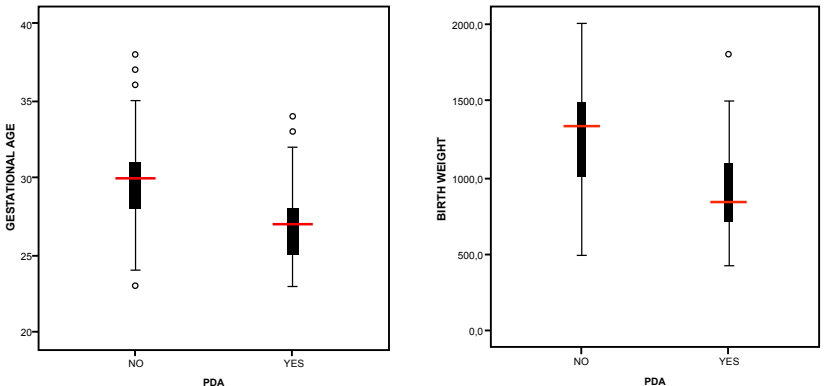

Figure 1: PDA according to birth weight and gestational age.

\begin{tabular}{|l|c|c|c|c|}
\hline Variables & OR & \multicolumn{2}{|c|}{ Cl 95\% } & $p$ \\
\hline Gender & & Lower & Upper & \\
\hline Gestational age (days) & 1.15 & 0.71 & 1.85 & 0.55 \\
\hline Birth weight (grams) & 0.68 & 0.61 & 0.75 & $<0.0001$ \\
\hline APGAR 1' & 0.99 & 0.995 & 0.997 & $<0.0001$ \\
\hline APGAR 5' & 0.77 & 0.68 & 0.86 & $<0.0001$ \\
\hline CRIB & 0.73 & 0.62 & 0.86 & $<0.0001$ \\
\hline SNAPPE II & 1.17 & 1.11 & 1.24 & $<0.0001$ \\
\hline Resuscitation delivery room & 1.03 & 1.02 & 1.04 & $<0.0001$ \\
\hline Surfactant administration & 13.1 & 3.11 & 55.1 & $<0.0001$ \\
\hline Antenatal corticotherapy & 8.12 & 4.13 & 15.95 & $<0.0001$ \\
\hline
\end{tabular}

Table 2: Univariate Logistic Regression analysis for PDA risk and protective factors.

who presented clinical criteria for PDA: murmur, bouncing pulses, prominent left ventricular impulse or noncardiovascular findings such as tachypnea, apnea, increased carbon dioxide retention or increased requirements for mechanical ventilation, unexplained by lung disease.

Infants with PDA had a lower mean birth weight (914.19 versus 1257.44 grams; $\mathrm{p}<0.001)$ and a lower mean gestational age $(27.06$ versus 29.77 weeks; $\mathrm{p}<0,0001$ ) (Figure 1).

Using an univariate logistic regression analysis (Table 2), lower gestational age and lower birth weight were risk factors for PDA. The higher Apgar scores at one and five minutes decreased the risk of PDA by $23 \%$ and $27 \%$, respectively. Need for resuscitation in the delivery room (manual ventilation, oxygen, intubation, chest compressions or adrenaline) as well as the clinical and mortality CRIB and SNAPPEII scoring systems were also risk factors at a significant level. The administration of surfactant increased by eightfold the risk of PDA.

Antenatal corticotherapy was not a protective factor for PDA.

The multivariate logistic regression model, adjusted for gestational age and using all these variables, identified birth weight [OR:0.997; CI (95\%):0.996-0.998] and use of surfactant [OR: 3.99; CI (95\%): $1.903-$ 8.386] as the only risk factors contributing with statistical significance (Table 3). We also evaluated the Area Under the Curve (AUC) and reported a PPV of $82 \%$ (Figure 2).

\section{Discussion}

Identification of risk factors for the patency of the DA is important not only because a persistent patent ductus arteriosus (PDA) in preterm infants can have significant clinical consequences, but also because treatment is not without complications. 


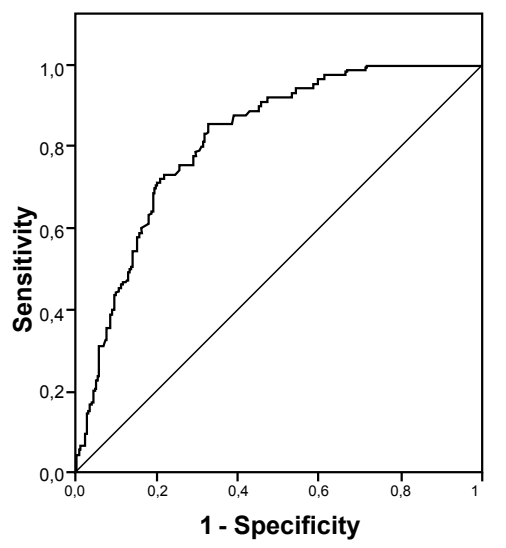

Figure 2: The AUC analysis for this model showed a predictive positive value of $82 \%$.

\begin{tabular}{|c|c|c|c|c|}
\hline Risk Factors & OR & \multicolumn{2}{|c|}{ IC 95\% } & $p$ \\
\hline & & Lower & Upper & \\
\hline Birth Weight & 0.997 & 0.996 & 0.998 & $<0.0001$ \\
\hline Surfactant administration & 3.995 & 1.903 & 8.38 & $<0.0001$ \\
\hline
\end{tabular}

Table 3: Multivariate Logistic Regression for PDA risk and protective factors.

The prevalence of PDA in our sample was $31.4 \%$, which is in accordance to the literature [11].

It is known that the mechanisms underlying functional DA closure depend on gestational maturity [1]. When using the univariate logistic regression, both lower gestational age (OR: 0.32; IC: 0.61-0.75) and lower birth weight (OR: 0.01; CI: 0.995-0.997) represented risk factors, the risk of PDA increasing 29\% for every less 100 grams and $93 \%$ for every week less of gestational age. In fact, in our study, birth weight represented a more significant risk factor than gestational age, given that Portuguese National Database included not only VLBW, but also less than 32 weeks infants, thus making birth weight a more representative parameter of prematurity.

Lower Apgar score at one (OR: 0.77; CI: 0.68-0.86) and at five minutes (OR: 0.73; CI: 0.62-0.86) were also risk factors, i.e. for one less Apgar point the PDA risk increases by 23 and 27\%, respectively. Ressuscitation in the delivery room (manual ventilation, oxygen, intubation, chest compressions or adrenaline) (OR 13,1; CI:3,11-55,1) represented a risk factor at a significant level [12].

The lower Apgar scores and the need for resuscitation can either be a manifestation of the infant's immaturity or caused by an acute obstetric condition such as asphyxia. Reller et al. [13] also found that in VLBW infants, birth asphyxia and severe RDS were significant risk factors for development of an early hemodynamically significant PDA.

Accordingly, the neonatal scoring systems CRIB (OR: 1,17; CI: 1.11-1.24), and SNAPPEII (OR: 1,03; CI: 1.02-1.04) also increased the risk of PDA. Besides immaturity and severity of illness frequently presented by preterm infants, other parameters, namely, the Apgar score, presence of metabolic acidosis and need for supplemental oxygen are also considered when scoring [14], all contributing to PDA, as noted above [13].

In our study, surfactant administration (OR: 8,12; CI: 4.1315.95) increased by eightfolds the risk of PDA. Although the effects of surfactant on the hemodynamics of the systemic and pulmonary circulation are still not well understood, related increase in PDA risk was also described by Soll and Ozek [15], who reported that prophylactic administration of synthetic surfactant to infants judged to be at risk of developing respiratory distress syndrome may lead to an increase in the incidence of patent ductus arteriosus and pulmonary hemorrhage. Clyman et al. [16] studied the effects of natural surfactant in 12 preterm lambs and identified a larger shunt through the ductus arteriosus after surfactant administration, which, they proposed, resulted from a significant drop in pulmonar vascular resistance. On the other hand, Sehgal et al. [17] suggested an increase in transductal diameter after surfactant treatment, which associated with the relative alterations in pulmonary and/or systemic hemodynamics and resistances, might contribute to significant change in the pulmonary and systemic blood flow.

Although steroids seem to change DA's sensitivity to PGE2, in our study, antenatal corticotherapy (OR: 0,81; CI: 0.44- 1.49) was not identified as a protective factor for PDA, probably due to the size of the sample.

When undertaking the multivariate logistic regression analysis adjusted to gestational age, only the birth weight (OR: 0,997; CI: 0.996-0.998) and the administration of surfactant (OR: 3,99; CI: 1.903-8.386) remained significant risk factors. These facts underline not only the importance of immaturity in the pathophysiology of PDA but also the likely effect of surfactant administration on pulmonary and systemic hemodynamics. The model used proved to be a good fit to predict PDA, as the AUC corresponded to a predictive positive value of $82 \%$, considered an excellent discrimination model [18].

\section{Conclusion}

Although with limitations resulting from its retrospective nature, this study confirmed the importance of identifying risk factors for PDA acting individually or in interaction with each other.

When adjusted to gestational age, the most important risk factors for PDA were the administration of surfactant and low birth weight, the latter increasing by $23 \%$, the risk of PDA for every 100 grams less. Although surfactant treatment leads to improved respiratory outcomes and survival in very low birth weight infants, the impact on hemodynamics of pulmonary and systemic circulation is still poorly understood. New trials to provide a better understanding of the precise impact of surfactant treatment on PDA are necessary. In our study, it increased the risk of PDA by an almost fourfold.

\section{References}

1. Schneider DJ, Moore JW (2006) Patent ductus arteriosus. Circulation 114 1873-1882.

2. Hamrick SEG, Hansmann G (2010) Patent Ductus Arteriosus of the Preterm Infant. Pediatrics 125: 1020-1030.

3. Hoffman JI, Kaplan S (2002) The incidence of congenital heart disease. J Am Coll Cardiol 39:1890-1900

4. (1993) The Vermont-Oxford Trials Network: very low birth weight outcomes for 1990. Investigators of the Vermont-Oxford Trials Network Database Project. Pediatrics 91: 540-545.

5. Richards J, Johnson A, Fox G, Campbell M (2009) A second course of ibuprofen is effective in the closure of a clinically significant PDA in ELBW infants. Pediatrics 124: e287-e293.

6. Clyman RI, Chorne N (2007) Patent ductus arteriosus: evidence for and against treatment. J Pediatr 150: 216-219.

7. Clyman RI (1987) Ductus arteriosus: current theories of prenatal and postnatal regulation. Semin Perinatol 11: 64-71. 
Citation: Nizarali Z, Marques T, Costa C, Barroso R, Cunha M (2012)Patent Ductus Arteriosus: Perinatal Risk Factors. J Neonatal Biol 1:109. doi:10.4172/2167-0897.1000109

Page 4 of 4

8. Clyman RI (2000) Ibuprofen and patent ductus arteriosus. N Engl J Med 343: 728-730.

9. Clyman RI, Waleh N, Black SM, Riemer RK, Mauray F, et al. (1998) Regulation of ductus arteriosus patency by nitric oxide in fetal lambs: the role of gestation, oxygen tension, and vasa vasorum. Pediatr Res 43: 633-644.

10. Wright LL, Verter J, Younes N, Stevenson D, Fanaroff AA, et al. (1995) Antenatal corticosteroid administration and neonatal outcome in very low birth weight infants: the NICHD Neonatal Research Network. Am J Obstet Gynecol 173: 269-274

11. Lemons JA, Bauer CR, Oh W, Korones SB, Papile LA, et al. (2001) Very low birth weight outcomes of the National Institute of Child health and human development neonatal research network, January 1995 through December 1996. NICHD Neonatal Research Network. Pediatrics 107: E1

12. Escumalha M, Gouveia C, Cunha M, Vale F, Machado MC (2005) Neonata morbidity and outcome of live born premature babies after attempted illegal abortion with misoprostol. Pediatr Nurs 31: 228-231.

13. Reller MD, Lorenz JM, Kotagal UR, Meyer RA, Kaplan S (1985)
Hemodynamically significant PDA: an echocardiographic and clinical assessment of incidence, natural history, and outcome in very low birth weight infants maintained in negative fluid balance. Pediatr Cardiol 6: 17-23.

14. Société Française d’Anesthésie et de Réanimation (retrieved in 8th May 2012).

15. Soll R, Özek E (2010) Prophylactic protein free synthetic surfactant for preventing morbidity and mortality in preterm infants. Cochrane Database of Systematic Reviews. DOI: 10.1002/14651858.CD001079.

16. Clyman RI, Jobe A, Heymann M, Ikegami M, Roman C, et al. (1982) Increased shunt through the patent ductus arteriosus after surfactant replacement therapy. J Pediatr 100: 101-107.

17. Sehgal A, Mak W, Dunn M, Kelly E, Whyte H, et al. (2010) Haemodynamic changes after delivery room surfactant administration to very low birth weight infants. Arch Dis Child Fetal Neonatal Ed 95: F345-F351.

18. Hosmer DW, Lemeshow S (2000) Applied Logistic Regression. Wiley Series in probability and statistics. (2ndedn), Wiley Interscience Publication. 